\title{
INTERNATIONAL SPACE STATION 2A ARRAY MODAL ANALYSIS
}

\author{
Michael Laible \\ The Boeing Company, 3700 Bay Area Blvd., Houston, Texas \\ Kristin Fitzpatrick \\ The Boeing Company, 3700 Bay Area Blvd. Houston, Texas \\ Michael Grygier \\ NASA, Johnson Space Center, Houston, Texas
}

\begin{abstract}
On December $9^{\text {th }}$ 2009, the International Space Station (ISS) 2A solar array mast experienced prolonged longeron shadowing during a Soyuz undocking. Analytical reconstruction of induced thermal and dynamic structural loads showed an exceedance of the mast buckling limit. Possible structural damage to the solar array mast could have occurred during this event. A Low fidelity video survey of the 2A mast showed no obvious damage of the mast longerons or battens. The decision was made to conduct an on-orbit dynamic test of the $2 \mathrm{~A}$ array on December $18^{\text {th }}$, 2009. The test included thruster pluming on the array while photogrammetry data was recorded. The test was similar to other Dedicated Thruster Firings (DTFs) that were performed to measure structural frequency and damping of a solar array. Results of the DTF indicated lower frequency mast modes than model predictions, thus leading to speculation of mast damage.
\end{abstract}

A detailed nonlinear analysis was performed on the 2A array model to assess possible solutions to modal differences. The setup of the parametric nonlinear trade study included the use of a detailed array model and the reduced mass and stiffness matrices of the entire ISS being applied to the array interface. The study revealed that the array attachment structure is nonlinear and thus was the source of error in the model prediction of mast modes. In addition, a detailed study was performed to determine mast mode sensitivity to mast longeron damage. This sensitivity study was performed to assess if the ISS program has sufficient instrumentation for mast damage detection.

KEYWORDS: Non-linear, Modal Analysis, Photogrammetry, Damage Detection

\subsection{INTRODUCTION}

The on-orbit construction of the International Space Station (ISS) began in November 1998, and was completed in July of 2011. The ISS consists of eight solar arrays for power generation. Each array is mounted on a rotating gear box for solar tracking and is deployed with a 4 longeron mast. Each mast is made of 32 bays consisting of longerons, fixed battens, flexible battens, and cable diagonals. Early in the ISS assembly process it was noted that thermal and dynamic conditions exist that could buckle a solar array mast longeron. This condition exists when one longeron is shadowed by another structure, thus causing asymmetric thermal loading in the mast longeron.

The ISS program developed a software tool to predict longeron shadowing events and to minimize periods of extreme loads. During the 19S Soyuz undocking December 1, 2009, the vehicle was in a long period of solar array longeron shadowing. The analysis predicted extreme loads in array 2A longeron and possible buckling. It was determined that an on-orbit test should be performed to analyze the dynamic response of the $2 \mathrm{~A}$ array to check for damage.

This test produced a significant frequency difference in the $1^{\text {st }}$ In Plane Array Mode compared to the analytical model and the other arrays. The ISS program requested a complete analysis of this event to determine if the $2 \mathrm{~A}$ array was damaged or not. This paper documents the analysis performed and investigates possible solutions to the dynamic differences of this array. In addition to the dynamic analysis, analysis was performed to determine if a longeron did fail, can the failure be detected from existing on-orbit instrumentation. 
Section 2.0 of this report presents the background of longeron shadowing and the specific 2A longeron shadowing event. Section 3.0 describes both the linear and nonlinear 2A array modal analyses performed and a comparison to the other ISS arrays. Section 4.0 outlines the analysis performed to determine if we can detect mast damage utilizing the instrumentation on-board ISS. Section 5.0 discusses the conclusions

\subsection{PROBLEM DESCRIPTION}

\subsection{ISS ARRAY LONGERON SHADOWING}

The ISS has eight solar arrays, each consisting of a mast, two solar cell blankets, and four blanket boxes. These masts are attached to the Beta Gimbal Assembly (BGA) and can rotate independently about the long axis of the mast. Fig. 1 illustrates the ISS configuration with the eight arrays rotated independently and the 2A Array; the focus of this paper.

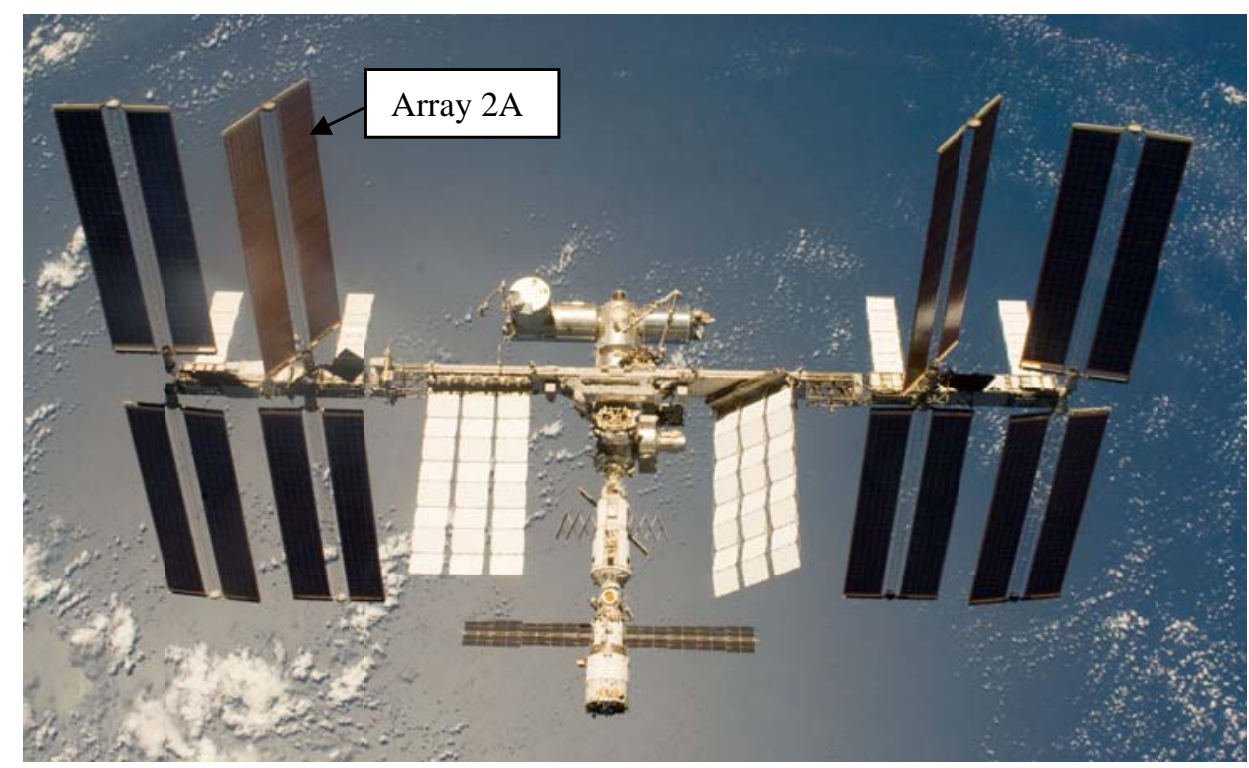

Fig. 1 International Space Station Assembly Complete

Each mast is made up of four longerons as shown in Fig. 2. If one longeron is shadowed and the others heated, two longerons will be in compression and others will be in tension. This can cause buckling of the longerons. Typical buckling and temperature values are shown in Fig. 2.The buckling starts at a combined dynamic and thermal load of 1340 lbs [1].

The ISS program performs a detailed longeron shadowing analysis and values are reported real-time. The ISS mission operation personnel will receive a warning if a longeron is shadowed and loads are at max limit values. When the warning is received the BGA is rotated to eliminate longeron shadowing.
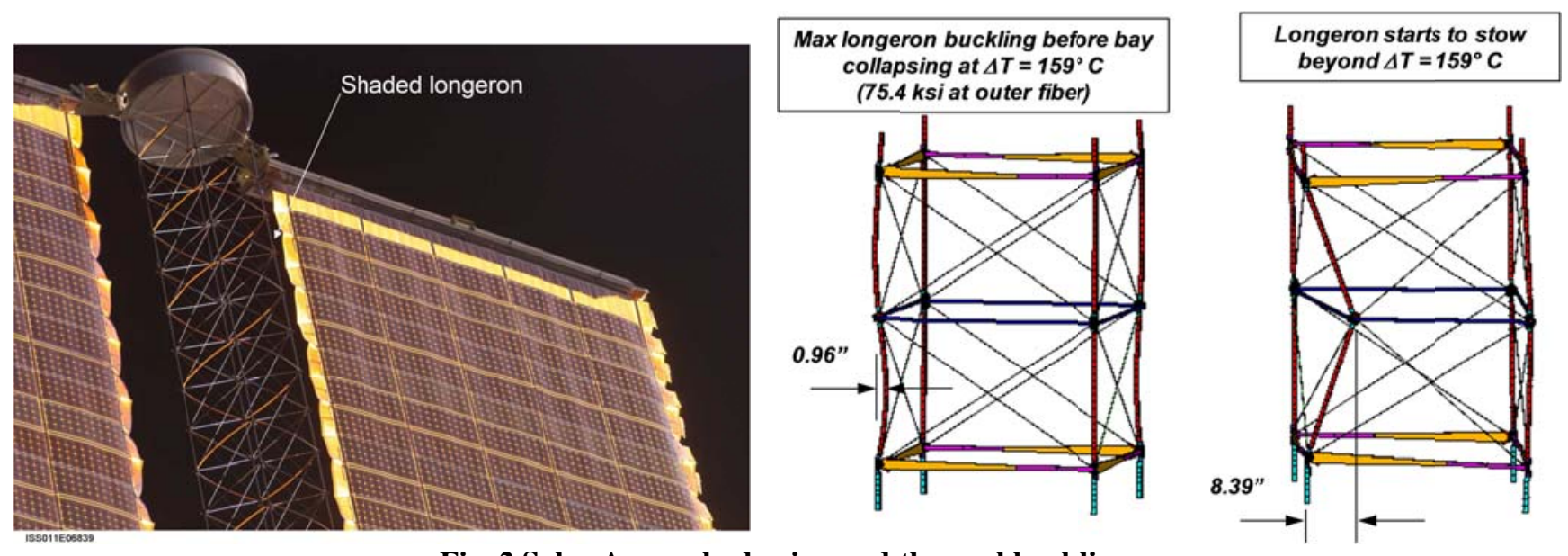

Fig. 2 Solar Array shadowing and thermal buckling 


\section{2}

2A ANOMOLY

During an ISS maneuver in December, 2009, the 2A Array experienced Longeron Shadowing for an extended period of time. Post flight analysis proved that the limit load was exceeded and that buckling could have occurred. To ensure structural integrity a detailed photo review was performed with no noticeable damage reported.

The ISS program then determined that a Dedicated Thruster Firing (DTF) test should be performed on the 2A Array to determine the modal structural properties. Instrumentation does not exist on the array mast itself; therefore, photogrammetry data was recorded and analyzed to determine the modal parameters of the array. The Image Science and Analysis Group (ISAG), at NASA JSC received analog video taken during the 2A DTF from two ISS external cameras [2]. Fig. 3 illustrates the camera views and jet plume direction toward the 2A Array. The thruster firing lasted for 1 second and was designed to excite the modes of the 2A Array.
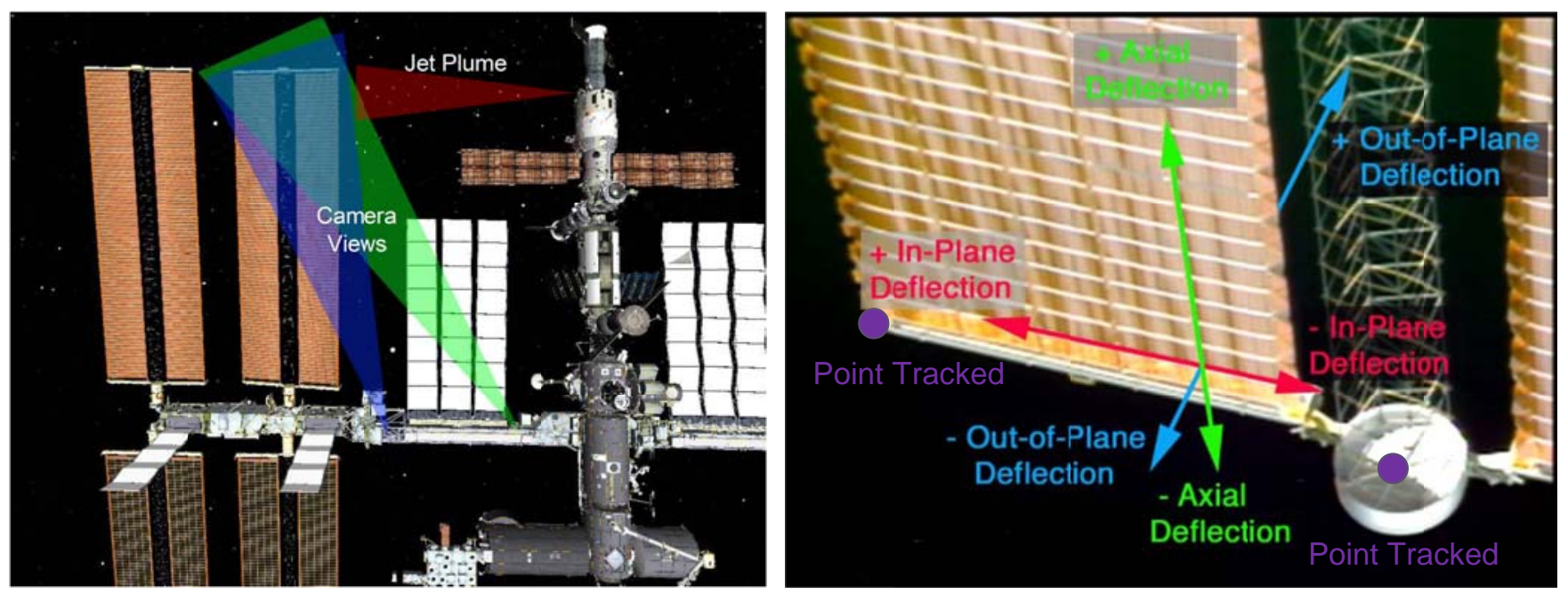

Fig. 3 ISS Camera Views, Jet Plume and Photogrammetry Coordinate Frame

The ISAG used their image processing software to track two points at the end of the 2A Solar Array Wing (SAW), Fig. 3. One point was on the mast cap located at the end of the mast of the solar array. The second tracked point was on the tip of the blanket box at the end of the solar array. The motion of each point was tracked in the video recorded from each of the two cameras and used to compute the relative displacement of the SAW tip in each axis, defined by the plane of the array during the DTF. Due to the high mathematical correlation between the axial and out of plane motion, the calculations were conducted in a way which constrains the axial position to a fixed value of 0 . This constraint is acceptable given that the motion of the array in the axial direction is significantly less than the In Plane (IP) or Out Of Plane (OOP) motions. The major modes observed from this DTF and previous DTF's are the $1^{\text {st }}$ OOP and $1^{\text {st }}$ IP modes. The frequency of the OOP and IP modes found for other arrays are between 0.06-0.0675 Hz and 0.09-.099 Hz, respectively.

When the photogrammetric analysis was completed, the time history data was low-pass filtered and the FFT was also computed. The OOP frequency was within the expected range but the IP frequency was $14 \%$ lower. The displacement time history and FFT of the array mast cap is illustrated in Fig. 4.

The Eigensystem Realization Algorithm (ERA) [3] was utilized to extract the modal parameters from the detrended photogrammetry data sets. The Modal Assurance Criterion (MAC) was calculated between the extracted mode shapes and the analytical model mode shapes. The comparison results between the extracted modal parameters from the data and the analytical modal parameters are summarized in Table 1 . The frequency of the first OOP test mode matched within $5 \%$ of the first 2A OOP analytical mode. The frequency difference between the $1^{\text {st }}$ IP test mode and IP analytical mode ranged from $14-17 \%$. 

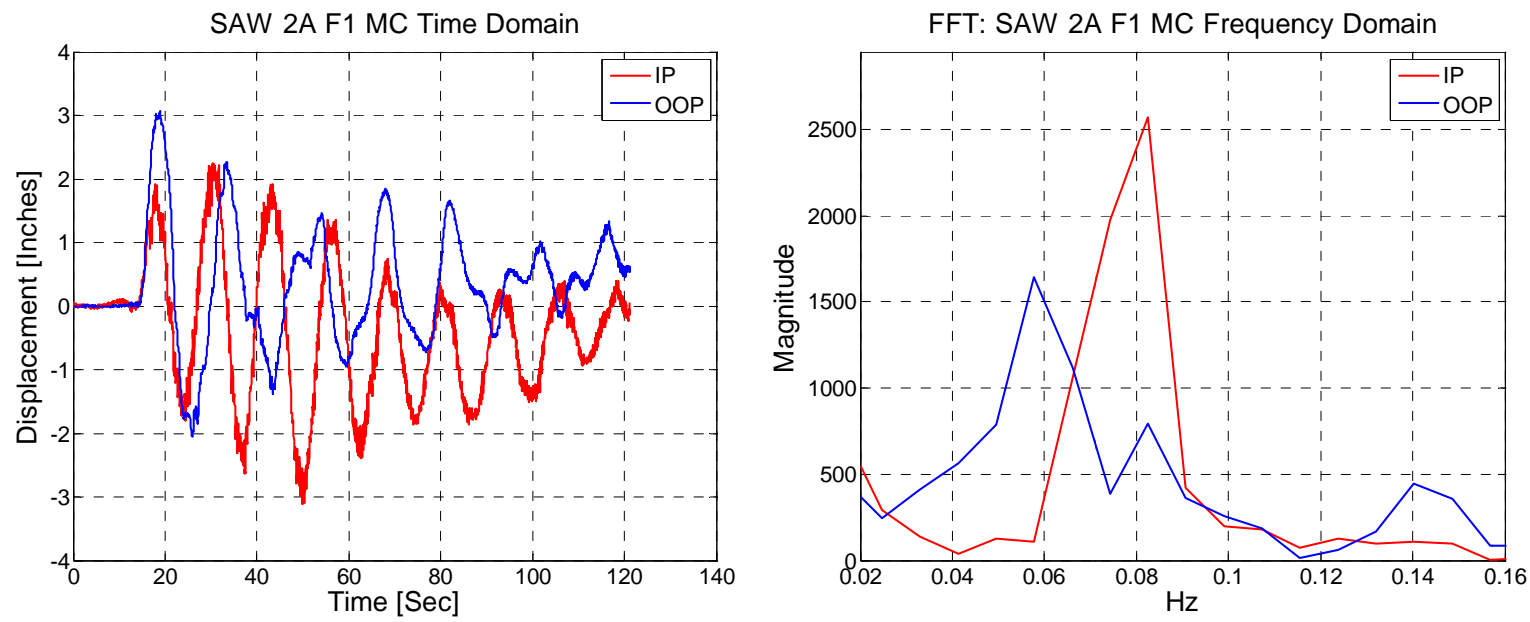

Fig. 4 Mast Cap Displacement Time History and FFT

Table 1 2A Array Test Modes versus Analytical Model Modes

\begin{tabular}{|c|c|c|c|c|c|c|c|c|}
\hline \multicolumn{4}{|c|}{ Test Data } & \multicolumn{5}{|c|}{ Analysis Data } \\
\hline Mode \# & $\begin{array}{c}\text { Freq. } \\
(\mathrm{Hz})\end{array}$ & $\begin{array}{c}\text { Damp. } \\
(\%)\end{array}$ & $\begin{array}{c}\text { EMAC } \\
(\%)\end{array}$ & $\begin{array}{c}\text { Mode } \\
\#\end{array}$ & $\begin{array}{l}\text { Freq. } \\
\text { (Hz) }\end{array}$ & $\begin{array}{c}\text { Freq. } \\
\text { Diff (\%) }\end{array}$ & MAC & Mode Description \\
\hline \multirow{5}{*}{1} & \multirow{5}{*}{0.0613} & \multirow{5}{*}{4.6} & \multirow{5}{*}{92.42} & 9 & 0.0597 & 2.68 & 0.951 & All SAWs OOP \\
\hline & & & & 10 & 0.0613 & 0.0 & 0.948 & All SAWs OOP \\
\hline & & & & 12 & 0.0648 & -5.40 & 0.942 & Port SAWs OOP \\
\hline & & & & 14 & 0.0651 & -5.84 & 0.943 & Port SAWs OOP \\
\hline & & & & 16 & 0.0665 & -7.82 & 0.940 & Port SAWs OOP \\
\hline \multirow{3}{*}{2} & \multirow{3}{*}{0.0798} & \multirow{3}{*}{3.3} & \multirow{3}{*}{96.12} & 17 & 0.0933 & -14.47 & 0.909 & Port SAWs IP \\
\hline & & & & 19 & 0.0964 & -17.22 & 0.904 & Port SAWs IP \\
\hline & & & & 22 & 0.0971 & -17.82 & 0.902 & Port SAWs IP \\
\hline
\end{tabular}

Fig. 5 illustrates the analytical mode shape of the OOP and IP modes. The figure is the MSC PATRAN model of the ISS system model, zoomed in on the 2A array. The mode number and frequency is shown for the OOP and IP 2A array modes.

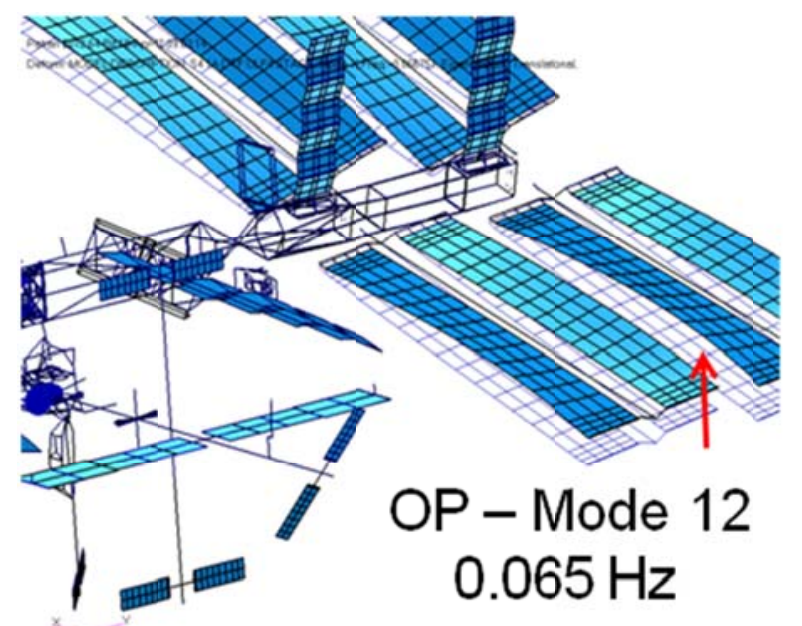

dotore, Dotomution

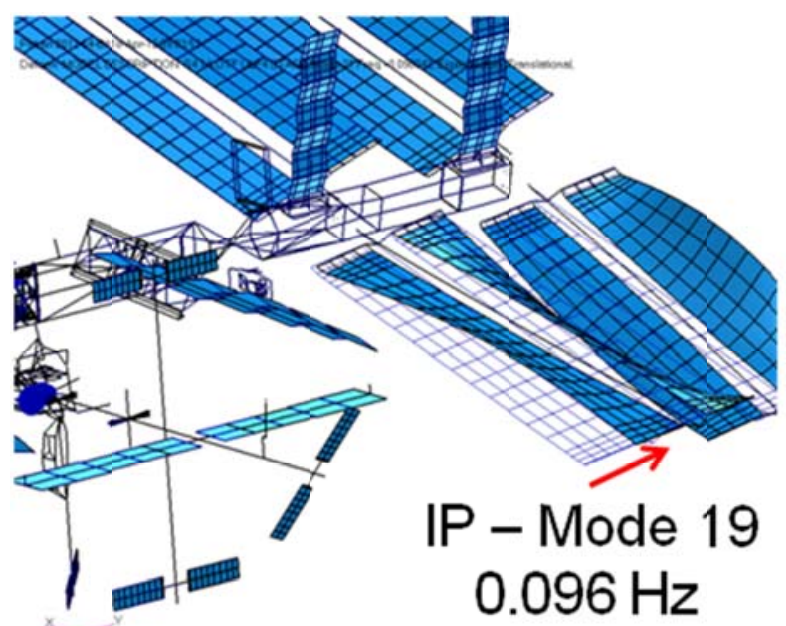

dotare Onomotion:

Fig. 5 Analytical Array Out of Plane and In Plane 


\subsection{A ARRAY MODAL ANALYSIS}

The 2A Solar array had experienced a sustained longeron shadow event. The analytical reconstruction of the event showed an excedence in the limit loads when combining the dynamic and thermal loads. An on-orbit dynamics test was performed and the IP mast mode was found to be $14 \%$ lower than what was expected when compared with the analytical dynamic model. In addition, the $1^{\text {st }}$ IP 2 A Array test mode was lower than what was previously seen with any other array on-orbit test. The large frequency difference between the IP test and analytical mode was a concern to the program and resulted in the request of a more detailed analysis to determine the cause of the difference.

The following detailed analysis was conducted to determine why the $1^{\text {st }}$ IP Array mode was lower and if damage of the array could be detected with modal analysis.

\subsection{LINEAR ANALYSIS}

The ISS loads system model is made up of over 90 super elements and has 35,000 dof. Each model takes about 60 minutes of computer time for the SOL 103. When performing time domain solutions (SOL 109 or 129) the time increases dramatically. This is an unmanageable model when performing parametric runs and numerous failure analysis time domain runs. To simplify the problem, a stiffness matrix was developed using the NASTRAN DMIG option with the boundary conditions being constrained at the approximate CG of the ISS and the other boundary being the 4 grids that the Solar array BGA attaches to ISS.

In addition, the solar array model used during nominal loads analysis has a simplified mast (1 Center Bar, 10 pieces) and did not model the individual longerons. To perform parametric studies of failed longerons the detailed mast model would have to be integrated into the simplified system model. Fig. 6 illustrates the baseline loads model (left) and the detailed mast model delivered from the developer (right). The highlighted CBARS are the longerons used for the failed analysis. The far right is a close up of the longeron model and cross battens. In failed longeron cases the complete connection is removed at positions depicted in Fig. 6 (MID and BASE). 


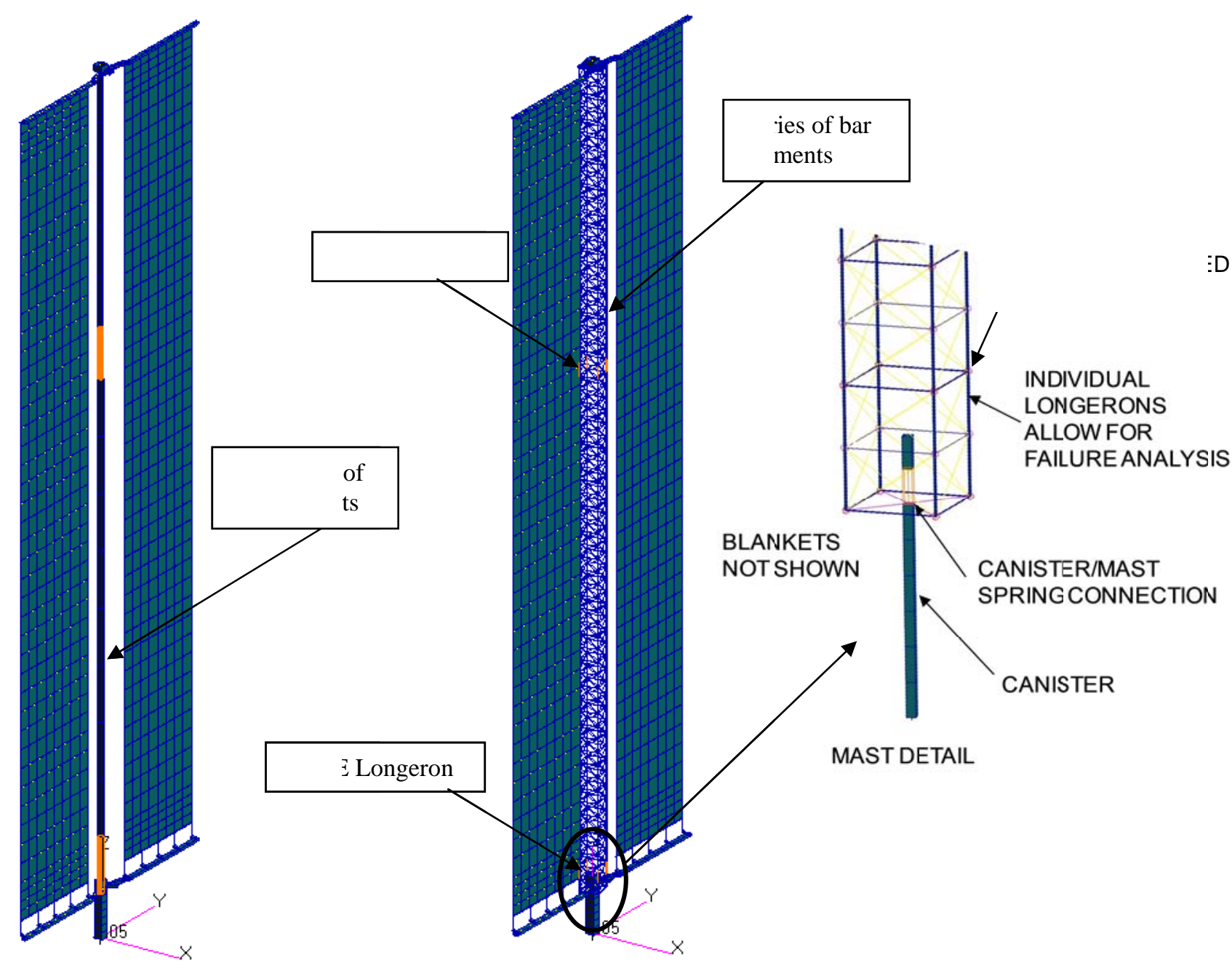

Baseline

The detailed array model was compared against the simplified baseline array model. A modal solution was performed with both models being constrained at the base coordinate frame as shown in Fig. 6. The frequency differences between the modes of each model were all within a $1 / 2 \%$. Once the model comparison was complete the detailed mast model was attached into the station stiffness and sensitivity studies were performed. Fig. 7 illustrates the station stiffness model with the detailed mast and array models.

The first run was the SOL 106, a non-linear solution, which involved pulling the blankets tight to the baseline spring tension. The blanket elements were pre-stressed in order to account for the effect of the blanket tension load. The blanket tension load was analyzed using geometric non-linear static analysis sequence (NASTRAN SOL 106) [4]. The differential stiffness matrix and coupled mass matrix are used in normal mode analysis solution sequence (NASTRAN SOL 103) and the EXTSEOUT card to build the DMIG of the array, PCH and ASM files. This is performed by restarting the SOL 106 run and using the EXTSEOUT card.

Now the ISS system model can be replicated by a NASTRAN run using the ISS DMIG, Solar array DMIG, and detailed fourbar BGA assembly. The time domain and modal solution runs could be performed with minimum computer time. Again this model is shown in Fig. 7 which also notes the chosen failed longerons for the analysis. These longerons were chosen from a separate analysis, which showed that these areas are the most likely to fail. 


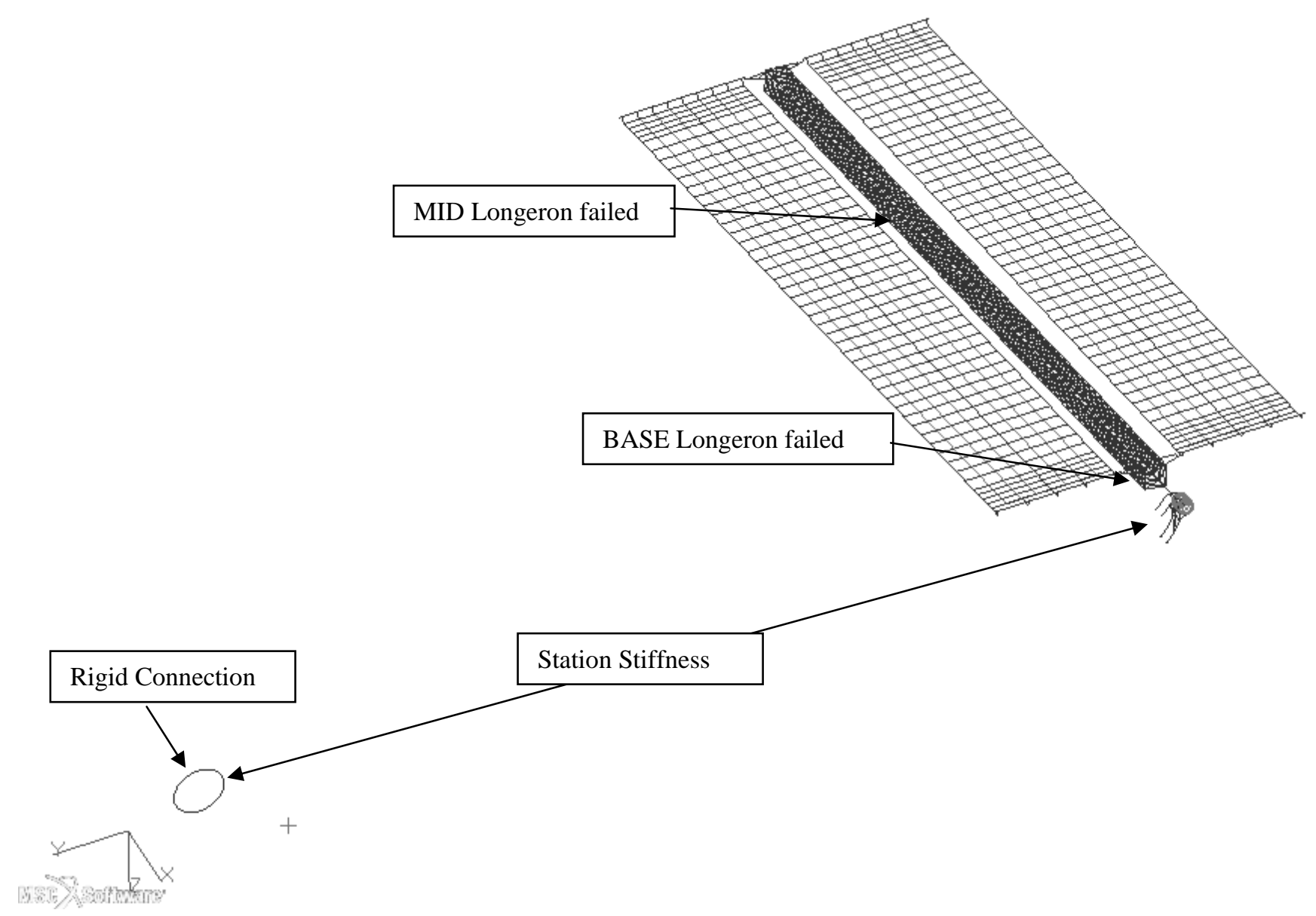

Fig. 7 ISS Stiffness with Detailed BGA and Array Model

The Boeing Loads and Dynamics group performs thruster plume analysis on all station arrays. The program that performs the analysis uses plume jet mass flow and impinges on individual plates modeling the array. The output is a force on each individual grid. The program has been validated with other array displacement checks. A special routine was developed to map force values and vectors for each array blanket. These force values were mapped to every array blanket and the mast cap. The array wing displacement was plotted and compared to the on-orbit data. These comparison plots are shown in Fig. 8. As can be seen by the displacement time history plots, the frequency of the on-orbit data and analytical data does not compare for the IP mode. This also was seen in the frequency domain.
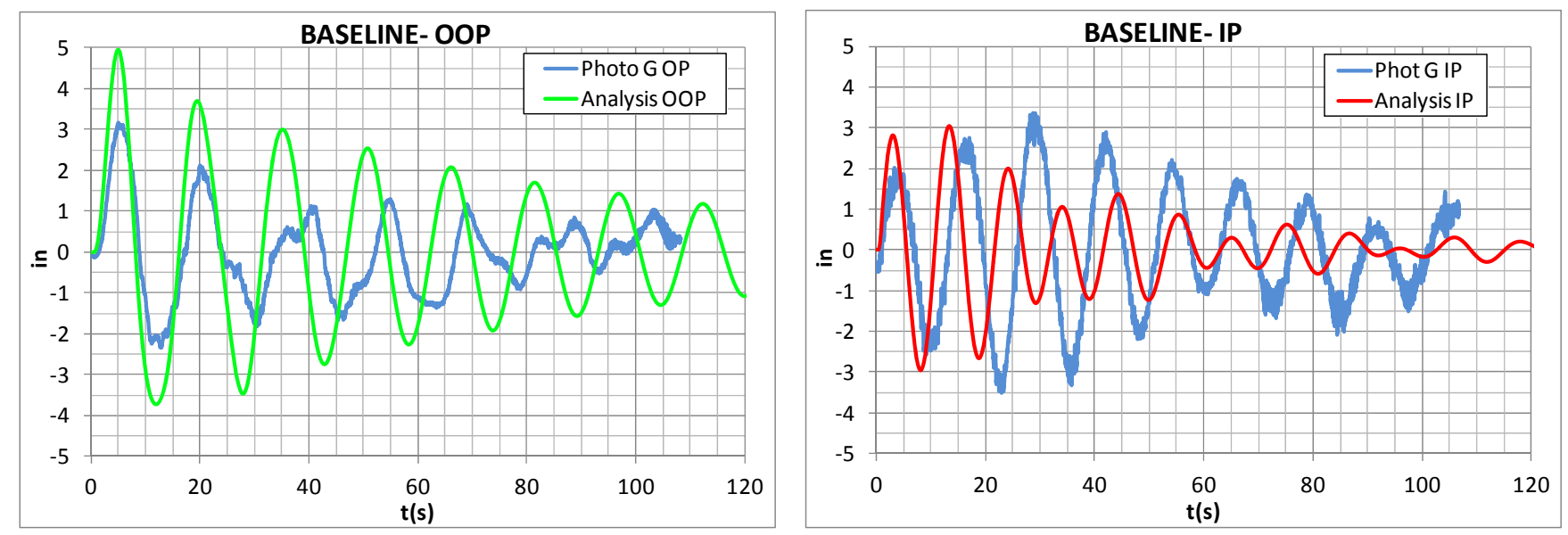

Fig. 8 Time Domain Comparison of Out of Plane and In Plane Test and Baseline Analytical Data 
In addition to the time domain runs, a parametric study was performed using the modal solution. Several models were created to conduct the parametric study; the Baseline array (BL 081), Baseline array with MID longeron partially failed (BL 081 MD1) and total fail (BL 081 MD1 TL), and the base longeron partially failed (BL 081 BS1) and base longeron totally failed (BL 081 BS1 TL). The results of this parametric study are shown in Table 2. As can be noted the Base longeron totally failed still shows a $10 \%$ frequency difference from the on-orbit test IP frequency.

These results indicate that the on-orbit IP frequency difference between the on orbit test and the analytical model cannot be explained by a longeron failure alone. Other areas had to be investigated.

Table 2 Array Frequency Comparison

\begin{tabular}{|l|c|c|c|c|c|c|c|c|}
\hline $\begin{array}{l}\text { Mode } \\
\text { Descrip }\end{array}$ & 2A DTF & BL 081 & $\begin{array}{c}\text { \% Diff } \\
\text { Test }\end{array}$ & $\begin{array}{c}\text { BL 081 } \\
\text { MD1 }\end{array}$ & $\begin{array}{c}\text { BL 081 } \\
\text { MD1 TL }\end{array}$ & $\begin{array}{c}\text { BL 081 } \\
\text { BS1 }\end{array}$ & $\begin{array}{c}\text { BL 081 } \\
\text { BS1 TL }\end{array}$ & $\begin{array}{c}\% \text { Diff } \\
\text { Test }\end{array}$ \\
\hline OP & 0.0602 & 0.0649 & $8 \%$ & 0.0646 & 0.0644 & 0.0635 & 0.0634 & $5 \%$ \\
IP & 0.0814 & 0.0969 & $17 \%$ & 0.0929 & 0.0926 & 0.0903 & 0.0898 & $10 \%$ \\
TOR \& IP & 0.103 & 0.0934 & $-10 \%$ & 0.0957 & 0.0953 & 0.0945 & 0.0945 & $-9 \%$ \\
Mast OP & 0.152 & 0.1519 & $0 \%$ & 0.1519 & 0.1519 & 0.1517 & 0.1517 & $0 \%$ \\
\hline
\end{tabular}

After a more detailed look of the system, it was determined that the IP mode stress was greatest in the four-bar linkages, which attaches the BGA to the ISS truss. In fact, the first two modes are dominated by the four-bar/BGA assembly. A detailed picture of the four-bar assembly is shown in Fig. 9.

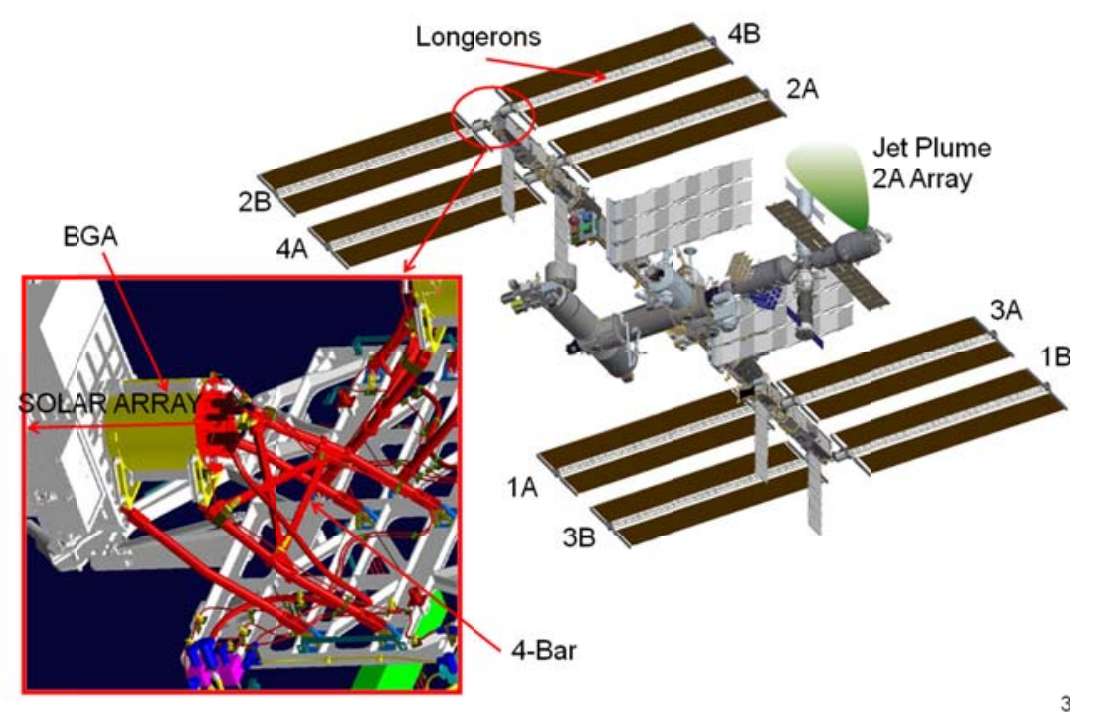

Fig. 9 ISS Four-Bar Assembly

\subsection{NON-LINEAR ANALYSIS}

To get a better understanding of the four-bar assembly mechanism and the inherent non-linearities, the ground test documents were reviewed. The ground test data illustrated an initial slippage followed by a high degree of bi-linearity, most notably between the +- My cases. Fig. 10 shows the strain gauge location and the derived moment output from the My input. The test data showed that some of the deflections were different in the plus and minus loading cases. Within each load case, the deflection verses load curves were relatively linear, but two curves emerged in some of the plus and minus load cases that were not (My shown in Fig. 10) [5, 6, 7].

This observation in the ground test data means that there was uneven slippage in some of the four-bar to clevis connections. After 10 iterations of the ground test the best agreement between the model and linear data required stiffness values be adjusted in the model four-bar to clevis springs, Mx (in-lb) = 450,000 to 900,000, My (in-lb) 650,000 to 2,280,000, and Mz (in-lb) 600,000 to 6,000,000. These new stiffness values were developed to correlate to the linear slope of the test data, thus the model is expected to be stiffer. 
All reports indicate that the non-linearities are mechanism slippage and are in the four-bar to IEA clevis connection.

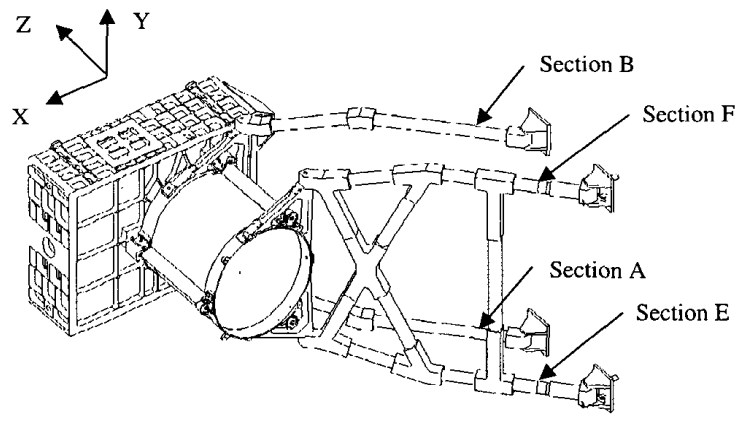

Figure 2 - Approximate Strain Gauge Locations (not to scale)
Plus and Minus My Loading

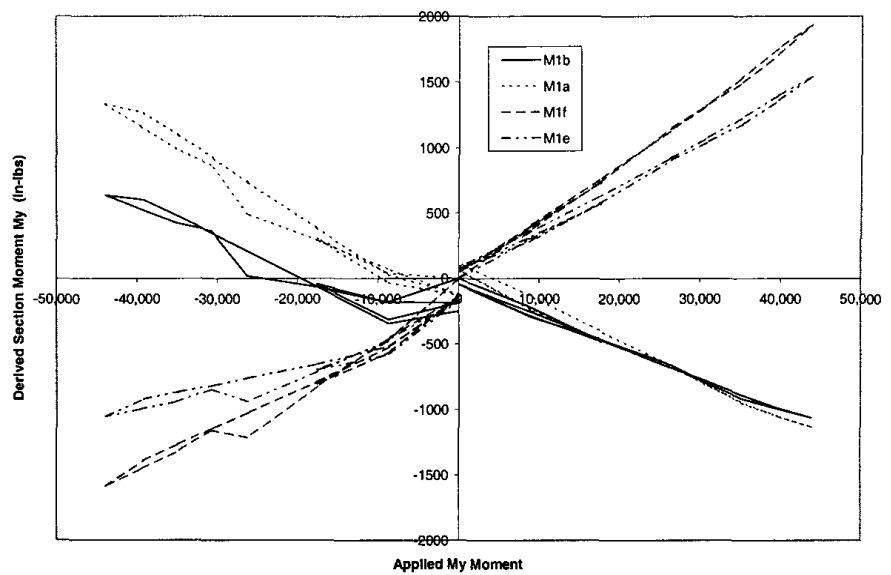

Fig. 10 Ground Test 4 Bar Assembly and Ground Test Stiffness Data

The ground test documents showed that non-linearities exist in the four bar connections. As noted earlier, the four-bar connections dominate the first two modes, OOP and IP. At this point a more detailed analysis was performed on the on-orbit data using the Boeing Test Analysis Correlation Solutions (BTACS) program. The BTACS system identification tool includes a method that extracts modal parameters within a set window over a prescribed period of time within the data set. The photogrammetry displacement data was analyzed using the system identification tool of the BTACS program. The modal parameters were computed every 0.67 seconds using a window of 60 seconds of data.

The frequency values, of the extracted modes, were then plotted for each time increment where the color of the data point represented the EMAC value, red being greater than $90 \%$ and orange greater than $80 \%$. Fig. 11 shows the results of the BTACS system identification analysis of the on-orbit data array data showing non-linearities of the $1^{\text {st }}$ OOP and $1^{\text {st }}$ IP Modes. The frequency of the OOP mode ranged from 0.06 to $0.068 \mathrm{~Hz}$ and IP 0.079 to $0.09 \mathrm{~Hz}$ over time, as the amplitude of the array displacement diminished.

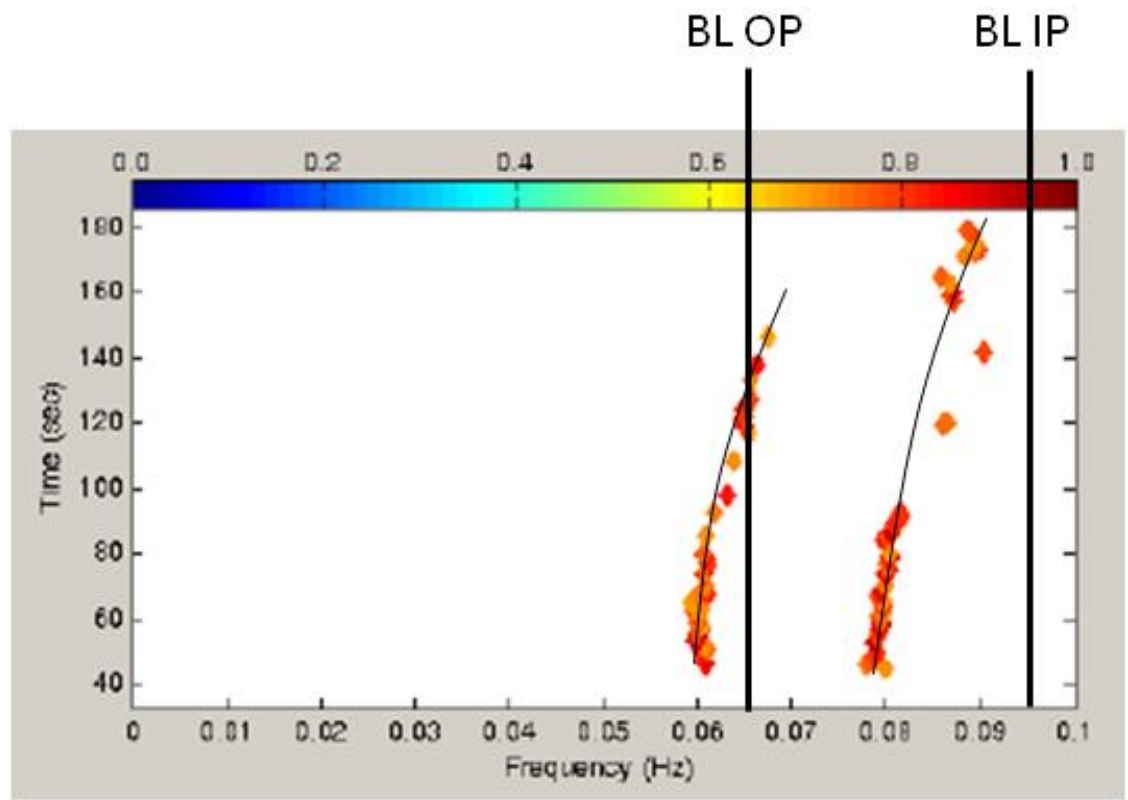

Fig. 11 Photogrammetry Data Mode Frequencies vs Time 
To better understand the mechanism of the four-bar clevis to truss connection, on-orbit photos were reviewed. As previously noted the ground test documents indicate that the non-linearities were most likely coming from the four-bar to truss clevis connection. Fig. 12 depicts the on-orbit photos showing the placement and close-up of the four-bar to clevis connection.

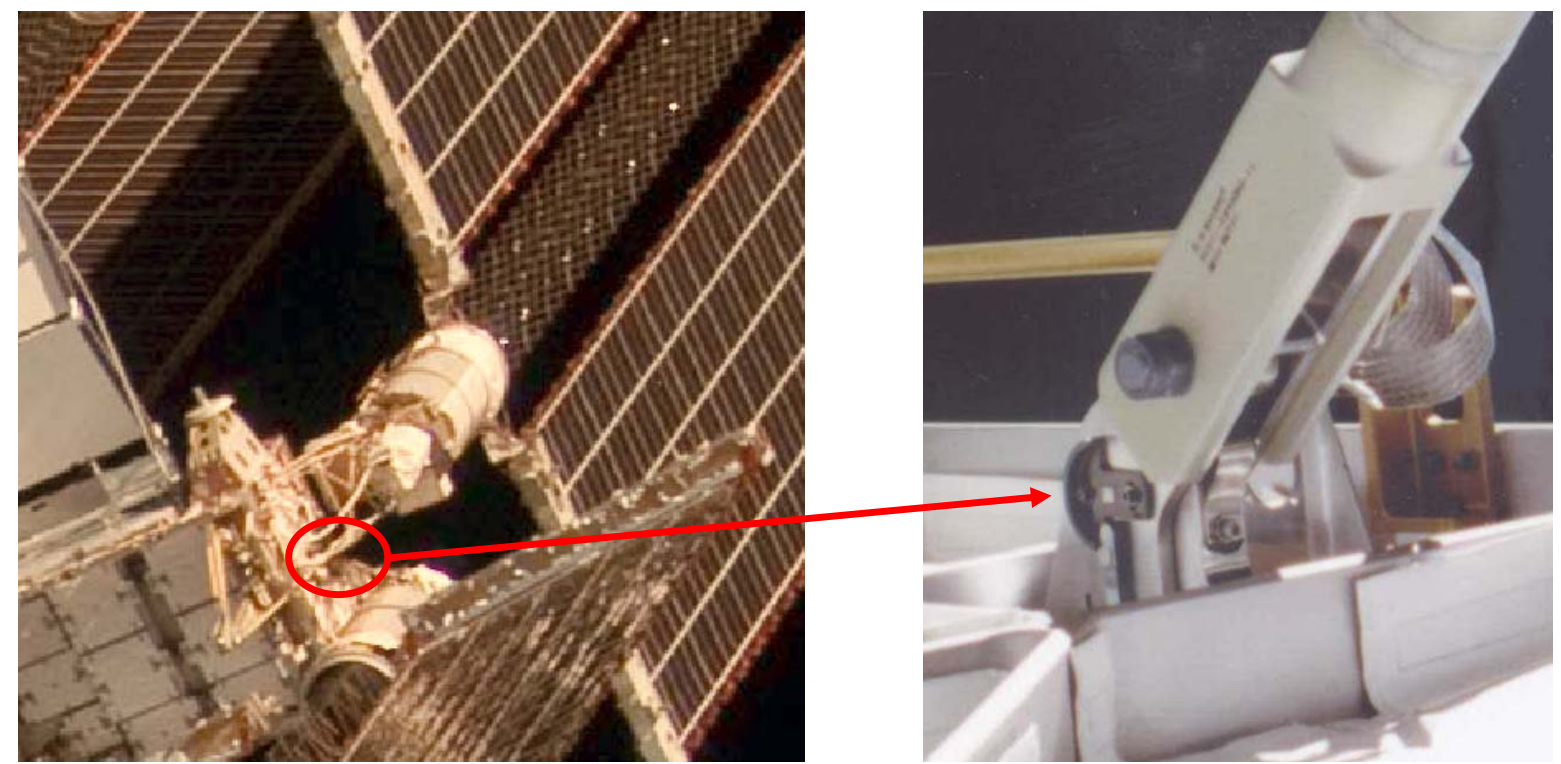

Fig. 12 Four-bar to Truss Mechanism

Fig. 12 illustrates the pin mechanism that locks the four-bar in the extended position (far right). This pin connection is modeled as a set of springs in the BGA detailed NASTRAN model. During the ground test it was decided to correlate the model to the linear stiff portion of the test data, thus increasing the rotational spring values as shown in Table 3, Colum 3 (Ground test BL 081). The original values of the model are shown in column 2 (Original).

A series of NASTRAN runs were performed modifying the four-bar to truss spring values. It was found that modifying the front two connections in DOF 1, 3, and 5 (see Fig. 13) would impact the frequency of the IP mode while having negligible effects on the frequency of the other modes. Column 4 of Table 3 contains the final spring values used for the analysis.

Table 3 BGA to Truss Spring Values

\begin{tabular}{|l|c|c|c|}
\hline & $\begin{array}{c}\text { Baseline } \\
\text { (in-lb) }\end{array}$ & $\begin{array}{c}\text { Ground test - } \\
\text { BL 081 (in-lb) }\end{array}$ & $\begin{array}{c}\text { Modified - BL 081 } \\
\text { DOF 1,3,5 Front (in-lb) }\end{array}$ \\
\hline CELAS2 DOF1 & 5500000 & 5500000 & 5000 \\
\hline CELAS2 DOF2 & 5000000 & 5000000 & 5000000 \\
\hline CELAS2 DOF3 & 300000 & 300000 & 5000 \\
\hline CELAS2 DOF4 & 450000 & 900000 & 900000 \\
\hline CELAS2 DOF5 & 650000 & 2280000 & 2280 \\
\hline CELAS2 DOF6 & 600000 & 6000000 & 6000000 \\
\hline
\end{tabular}




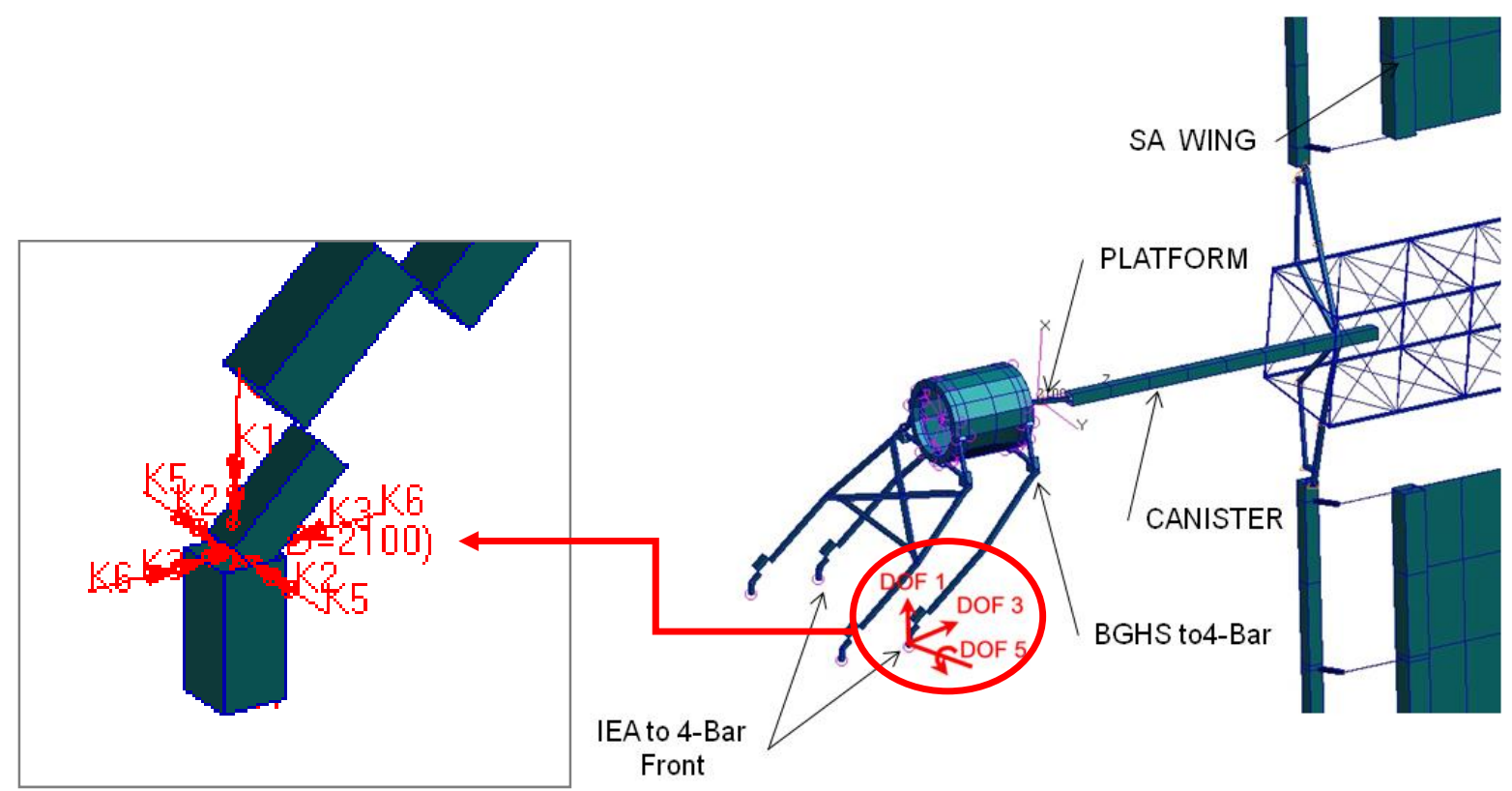

Fig. 13 Modified BGA Description

After all the runs with spring reductions were complete, the final OOP and IP mode frequency values were checked against the baseline mode and the on-orbit test. Table 4 illustrates the final frequency values and the percent frequency difference from the on-orbit test. The modified spring values changed the frequency of the IP mode without affecting the frequency other modes. These results allowed for a plausible explanation of the modal discrepancies of the IP frequency difference. It must be noted that this is a linear solution and that we saw non-linear results from the on-orbit test.

Table 4 Analytical Results of Modified BGA

\begin{tabular}{|cc|c|c|c|c|}
\hline On-Orbit Test & $\begin{array}{c}\text { BL 081 } \\
(\mathrm{Hz})\end{array}$ & $\begin{array}{c}\text { \% Diff } \\
\text { Test }\end{array}$ & $\begin{array}{c}\text { BL 081 DOF 1, } \\
\text { 3, 5 Front (Hz) }\end{array}$ & $\begin{array}{c}\% \text { Diff } \\
\text { Test }\end{array}$ \\
\hline 0.0602 & OOP & 0.065 & $8 \%$ & 0.061 & $1 \%$ \\
0.0814 & IP & 0.097 & $17 \%$ & 0.079 & $-3 \%$ \\
0.103 & TOR & 0.096 & $-7 \%$ & 0.096 & $-7 \%$ \\
0.152 & & 0.152 & $0 \%$ & 0.151 & $-1 \%$ \\
\hline
\end{tabular}

To account for the non-linear results seen in the on orbit photogrammetry data, GAP elements were used for the four-bar to truss clevis connection. The solution 129 was used for this analysis. Numerous runs were performed using GAP elements and the NOLIN card. The final analysis was performed using the NASTRAN GAP elements with varying axial stiffness values depending on open or closed gap. To model the on-orbit structure the stiffness was modeled to be less with an open gap. The closed gap stiffness is the same as the baseline A recap of the GAP card values are shown in table 5.

Table 5 GAP Stiffness Values

\begin{tabular}{|l|c|c|c|}
\hline & GAP Disp. (in) & $\begin{array}{c}\text { GAP Closed } \\
\text { Stiffness (in-lb) }\end{array}$ & $\begin{array}{c}\text { GAP Open } \\
\text { Stiffness (in-lb) }\end{array}$ \\
\hline DOF1 & .00005 & 5500000 & 5000 \\
\hline DOF2 & No Gap & 5000000 & 5000000 \\
\hline DOF3 & .0001 & 300000 & 5000 \\
\hline DOF4 & No Gap & 900000 & 900000 \\
\hline DOF5 & No Gap & 2280 & 2280 \\
\hline DOF6 & No Gap & 6000000 & 6000000 \\
\hline
\end{tabular}


The GAP elements were used on the four-bar to truss clevis on the front locations only. The initial gap open was determined by performing nominal plume runs and plotting the relative displacement between the GRIDS with the baseline spring constant. The exact GAP opened value was determined after several runs and acceptable results were achieved.

Once the proper GAP parameters were achieved, a time domain SOL 129 was performed. When performing non-linear transient analysis, the damping value is specified with the W3 parameter and is the damping at a specified mode. The frequency used for this was a split between OOP and IP mode and was valued at $2 \%$. The comparison time domain of the on-orbit test data and the non-linear analytical data is shown in Fig. 14. As can be noted the comparison is much better than the baseline (Fig. 8) and considered to be a good analytical representation of the on-orbit structure.
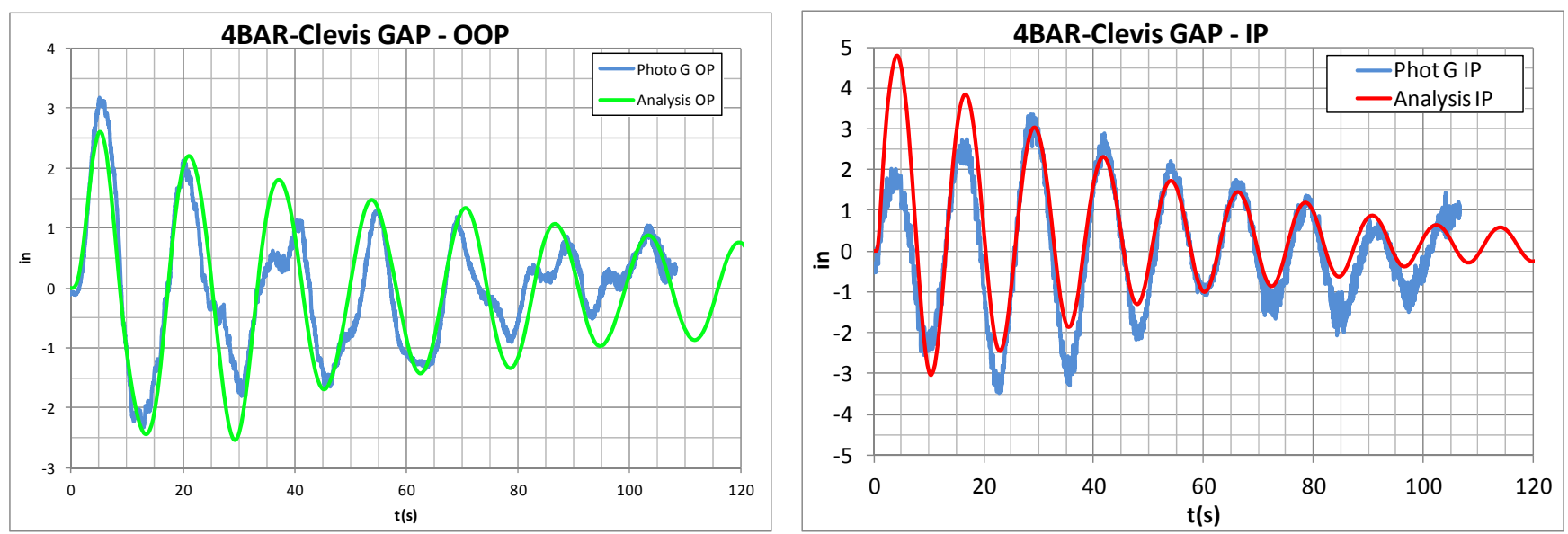

Fig. 14 On-Orbit versus Analytical Non-linear Time Domain Data

In addition to the time domain of the individual OOP and IP displacement of the array, the overall relative displacement of the spring grids were plotted. Fig. 15 shows the relative displacement of the front four-bars to truss clevis. The maximum displacement is 0.0175 ”. This displacement is a little more than double the complete tolerance stack up of the four-bar mechanism. The tolerance stack up of the four-bar clevis to truss connection is 0.0073 ”.

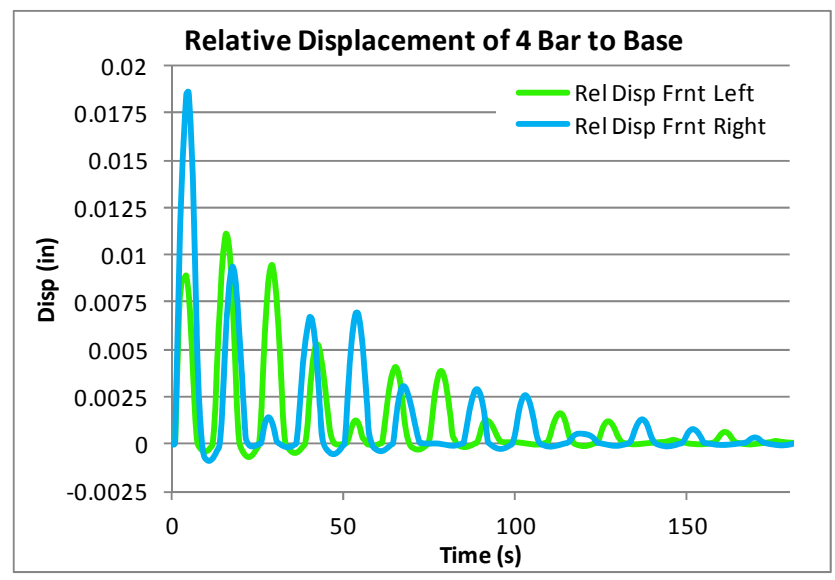

Fig. 15 Relative Displacement of Front Four-bar Clevis

For a 'quick look' analysis the softened springs were used on the boundary connections of the starboard truss IEA super element and the 2A BGA super element in the full detailed ISS system model. This model has all eight arrays thus it will have eight OOP modes, eight IP modes, and eight torsional array modes.

Table 6 compares the system model baseline modes and the 2A array reduced boundary connection model modes. It is noted, in bold, the 2A IP array mode of the modified model is lowered by the amount seen on-orbit. The mode shape comparison of the test modes and the modified model modes matched, and with the lower frequency value, would have deemed the array nominal if this was in the original analytical model when compared to on orbit 2A DTF. 
Table 6 ISS Modal Comparison of Baseline and Modified

\begin{tabular}{c|l||c|l||c|}
\multicolumn{1}{c|}{$\begin{array}{c}\text { Baseline } \\
\text { Mode }(\mathrm{Hz})\end{array}$} & Mode Description (Baseline) & $\begin{array}{c}\text { DOF } 135 \\
\text { Mode }(\mathrm{Hz})\end{array}$ & Mode Description (Modified) & $\%$ Diff \\
\hline 0.05973 & OOP PORT/STBD & 0.05884 & OOP PORT/2A & $-1.5 \%$ \\
0.06134 & OOP PORT/STBD & 0.06071 & OOP PORT/STBD & $-1.0 \%$ \\
0.06472 & OOP STBD & 0.06472 & OOP STBD & $0.0 \%$ \\
0.06484 & OOP PORT/2A & 0.06294 & OOP PORT/2A & $-3.0 \%$ \\
0.06499 & OOP STBD & 0.06499 & OOP STBD & $0.0 \%$ \\
0.06511 & OOP PORT & 0.06497 & OOP PORT & $-0.2 \%$ \\
0.06566 & OOP STBD & 0.06566 & OOP STBD & $0.0 \%$ \\
0.06648 & OOP PORT & 0.06628 & OOP PORT & $-0.3 \%$ \\
\hline 0.09333 & IP PORT Sym & $\mathbf{0 . 0 8 1 2 8}$ & IP 2a & $-\mathbf{1 4 . 8} \%$ \\
0.09566 & IP STBD Sym & 0.09568 & IP STBD Sym & $0.0 \%$ \\
$\mathbf{0 . 0 9 6 3 9}$ & IP PORT/2a & 0.09473 & IP PORT Sym & $-1.8 \%$ \\
0.09664 & IP STBD Anti-Sym & 0.09664 & IP STBD Anti-Sym & $0.0 \%$ \\
0.09676 & IP STBD & 0.09676 & IP STBD Anti-Sym & $0.0 \%$ \\
0.09707 & IP PORT, STBD anti-Sym & 0.09700 & IP PORT Anti-Sym, STBD & $-0.1 \%$ \\
0.09713 & IP PORT Anti-Sym, STBD & 0.09713 & IP PORT, STBD Anti-Sym & $0.0 \%$ \\
0.09812 & IP PORT Anti-Sym & 0.09811 & IP PORT Anti-Sym & $0.0 \%$ \\
\hline 0.09961 & TOR STBD & 0.09961 & TOR STBD & $0.0 \%$ \\
0.09968 & TOR STBD & 0.09968 & TOR STBD & $0.0 \%$ \\
0.09974 & TOR STBD & 0.09974 & TOR STBD & $0.0 \%$ \\
0.09976 & TOR PORT & 0.09978 & TOR PORT & $0.0 \%$ \\
0.09977 & TOR STBD & 0.09977 & TOR STBD & $0.0 \%$ \\
0.09995 & TOR PORT & 0.09967 & TOR PORT & $-0.3 \%$ \\
0.10025 & TOR PORT & 0.10022 & TOR PORT & $0.0 \%$ \\
0.10036 & TOR PORT & 0.10036 & TOR PORT & $0.0 \%$
\end{tabular}

\subsection{MAST DAMAGE SENSITIVITY STUDY}

In addition to the analysis performed to investigate the array mode frequency difference, it was asked if the current ISS instrumentation would allow for mast damage to be detected. A detailed study was performed to investigate if a longeron failure could be detected with current instrumentation.

The only instrumentation on orbit to measure ISS array modes is the photogrammetry system. The photogrammetry analysis needs at least two cameras on each area being investigated. It is possible but very difficult to get four cameras dedicated for an array test. For this study it was decided to use four cameras. Fig. 16 illustrates the two areas the cameras would be pointed, one set at the tip and one set at the midpoint, spanning the most credible failure area. 


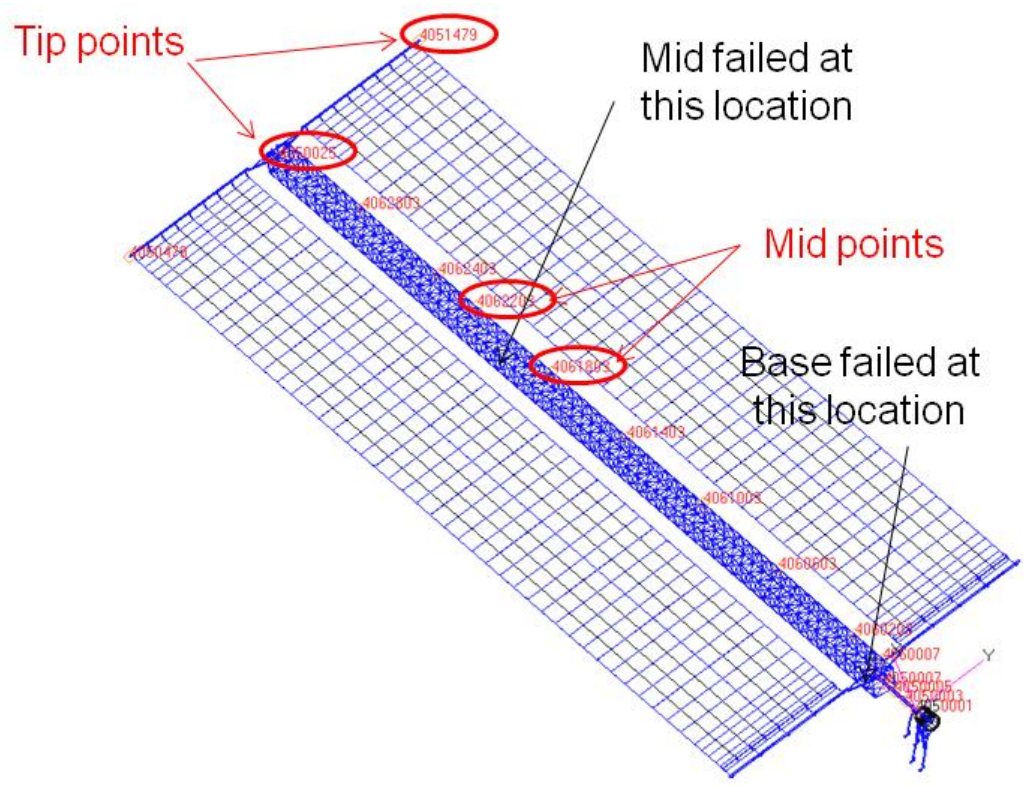

Fig. 16 Array Camera Viewing Locations

A set of SOL 103, modal solution, runs were performed on the baseline array model, failed at mid model, and failed at base model. The modal parameters for each model was output and compared to the baseline model modal parameters. For each run the frequency difference and MAC was calculated. The baseline model has over 700 modes from 0-5.5 Hz. To reduce the amount of modes to investigate, only modes containing $2 \%$ or greater kinetic energy in the array mast were saved. This reduced the problem down to 60 modes. It also must be mentioned that this is a total failure of the longeron and does not assume partial fractures.

Once the major modes were selected, the MAC was calculated using the four grids as noted in Fig. 16. Table 7 summarizes the data results for the mast failed at mid model and Table 8 summarizes the data for the mast failed at base model.

Table 7 is the summary of the failed longeron at the mid point of the mast. The torsion mode has a low MAC between the baseline and damaged model but it would be difficult to detect this with the cameras available and determining if this is the results of the four-bar contribution or mast damage. The next possible mode for detecting mast damage was the $0.677 \mathrm{~Hz}$ mast bending mode. The failed mast does show a lower MAC value and mode frequency. The best possibility of damage detection is the additional mode in the failed case at $1.2868 \mathrm{~Hz}$ (highlighted in bold). When performing the MAC the best match is the baseline mode at $1.5107 \mathrm{~Hz}$. This mode would be the best mode to detect a total longeron failure at mid mast and the comparison mode shape is illustrated in Fig. 17. Some other modes exist above $4 \mathrm{~Hz}$ but it is difficult on orbit to physically excite modes at that high of a frequency and the reliability of photogrammetry to capture the modes at that frequency is unknown, due to the frame rate of the cameras of 15 or $30 \mathrm{~Hz}$.

\begin{tabular}{c|c|c|c|l|c}
\multicolumn{7}{|c|}{$\begin{array}{c}\text { Table 7 BGA at 81 deg Damaged at MID } \\
\text { \% Dif Freq }\end{array}$} & \multicolumn{1}{|c}{ Mode Description } & \% KE Mast \\
\hline 0.093 & 0.090 & 0.758 & $-3.2 \%$ & TORSION & $3 \%$ \\
0.6777 & 0.6247 & 0.823 & $-7.8 \%$ & MAST BENDING WITH BLANKET (anti) BENDING & $5 \%$ \\
1.5107 & 1.259 & 0.745 & $-16.7 \%$ & OUT PLANE BENDING WITH LOWER BLNK BOX & $20 \%$ \\
$\mathbf{1 . 5 1 0 7}$ & $\mathbf{1 . 2 8 6 8}$ & $\mathbf{0 . 7 2 2}$ & $\mathbf{- 1 4 . 8 \%}$ & ADDED MODE FROM MID DAMAGE & $\mathbf{2 0 \%}$ \\
2.3272 & 2.2607 & 0.752 & $-2.9 \%$ & GOOD 1st IN PLANE BENDING & $24 \%$ \\
4.344 & 4.06 & 0.642 & $-6.5 \%$ & 45 DEG PLANE 2ND BENDING & $2 \%$ \\
4.3824 & 4.6232 & 0.545 & $5.5 \%$ & OUT PLANE 2ND BENDING & $52 \%$
\end{tabular}




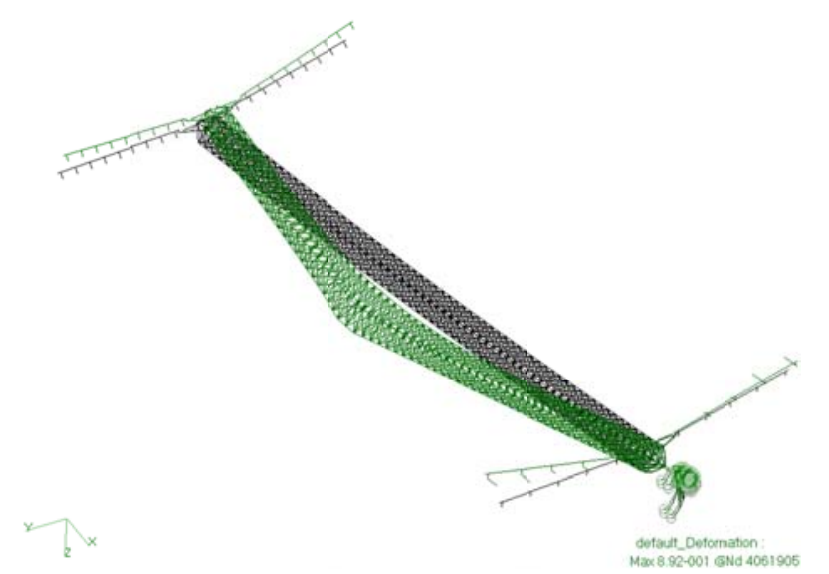

Fig. 17 Mast Mode Shape Comparison with MID Longeron Failure

Table 8 illustrates the frequency difference and MAC values between baseline model and the failed longeron at the base of the mast model. Once again the first torsion mode may be difficult to determine if the difference is caused by the mast or four-bar damage but with the higher KE it should be easier to excite on orbit. The modes above $4 \mathrm{~Hz}$ seem to have the best chance of detecting mast damage, but again the modes at this high a frequency are difficult to excite on orbit and it is unknown if modes in this frequency range can be reliably detected using photogrammetry.

\begin{tabular}{c|c|c|c|l|c}
\multicolumn{7}{c}{ Table 8 BGA at 81 Deg Damaged at Base } \\
BL Freq. & Fail Freq. & MAC & \% Dif Freq & \multicolumn{1}{|c}{ Mode Description } & $\%$ KE Mast \\
\hline 0.093 & 0.090 & 0.758 & $-3.4 \%$ & TORSION & $19.2 \%$ \\
1.001 & 0.980 & 0.924 & $-2.1 \%$ & MAST IN PLANE FIRST BENDING & $9 \%$ \\
2.327 & 2.254 & 0.984 & $-3.1 \%$ & GOOD 1st IN PLANE BENDING & $24 \%$ \\
4.344 & 4.083 & 0.602 & $-6.0 \%$ & 45 DEG PLANE 2ND BENDING & $2 \%$ \\
4.382 & 4.083 & 0.915 & $-6.8 \%$ & OUT PLANE 2ND BENDING & $52 \%$
\end{tabular}

The final conclusions are that a mast failure can be detected with modes above $1 \mathrm{~Hz}$ for MID failure and above $2 \mathrm{~Hz}$ for the base failure. The limitation of the mast failure detection using existing photogrammetry is the ability of only having two areas to track. Mode shape differences are easier to detect when tracking four or more areas. An exhaustive study of the optimal tracking areas was not performed and could be an area of improvement. In addition, the program is developing high definition cameras that would enhance the detection process but would still be limited to tracking only two areas.

\subsection{CONCLUSIONS}

The 2A ISS array was subjected to extreme limit loads from a longeron shadowing event. The longeron shadowing event may cause a thermal buckling of the longeron on the ISS solar array mast. To check for structural integrity of the array, a photo survey was conducted and an on-orbit modal test was performed. No damage was found from the photo survey but the on-orbit modal test showed a frequency difference in the $1^{\text {st }}$ IP Array mode. Through analysis it was found that this frequency shift could not be explained by mast damage alone, but in fact may be a non-linear characteristic of the BGA fourbar clevis to truss attachment. Modal solutions proved that by softening the front four-bars that the $1^{\text {st }}$ IP mode frequency was lowered without affecting the other modes' frequencies. This was exactly what was observed in the on-orbit test. A simplified station model was developed with the detailed solar array model to perform time domain NASTRAN runs. The time domain runs were performed with the soft front four-bars with good results but still was not matching the on-orbit data.

It was found that the on-orbit 2A array displacement data increases in frequency as displacement amplitude decreases. This indicates a non-linear mechanism. This non-linear phenomenon was modeled using NASTRAN gaps with the baseline stiffness of the front four-bars when the Gap was closed and when it was opened the soft spring values were applied. The time domain displacement results matched the on-orbit test. It was concluded that the non-linearities could be attributed to gaps, gaps with pre-loads, and thermal effects. It was also determined that if a longeron on the array mast was damaged, completely separated, that it would be difficult to measure with current instrumentation, but with additional and higher quality cameras, it would be possible. 


\subsection{REFERENCES}

1. Solar Array Mast Buckling Report, ATK Space Systems 1163D3883, June 10, 2010

2. P4-2A Photogrammetry Results, NASA-JSC-Image Science and Analysis Group, January 5, 2010

3. Juang, J.N., Pappa, R.S., "An Eigensystem Realization Algorithm for Modal Parameter Identification and Model Reduction,” J. GUIDANCE, Vol. 8, No. 5, pp. 620-627, 1985.

4. Space Station PG-2 Fully Deployed Solar Array Nastran Dynamic Model, EM NO. SSSA57, Lockhee Martin Missiles and Space, C. C. Tang, Febraury, 10, 1997

5. BGA Static Test On-Orbit Deployed Loads Model Correlation, Boeing Memorandum EID-05475, April 6, 2000

6. BGA On-Orbit Static Test/Finite Element Model Correlation, Boeing Memorandum EID-05379, April 18. 2000

7. Qualification Mast Cannister Stiffness, Strength, and Strutural Alignment test Report, Lockheed 518D972, May 24, 1996

8. MSC NASTRAN Quick Reference Guide, MSC NASTRAN, 2008 